\title{
ESTUDO DO AUMENTO DA BIODEGRADABILIDADE DE CHORUME DE ATERRO SANITÁRIO
}

\author{
A. S. CASSINI ${ }^{1}$, L. R. ALVES ${ }^{1}$ e I. C. TESSARO ${ }^{1}$ \\ ${ }^{1}$ Universidade Federal do Rio Grande do Sul, Departamento de Engenharia Química \\ E-mail para contato: alinesc@enq.ufrgs.br
}

\begin{abstract}
RESUMO - Os resíduos sólidos urbanos constituem um grande problema para a sociedade; grande parte destes são depositados em aterros sanitários. Esse depósito gera a formação do chorume, caracterizado pela alta quantidade de matéria orgânica, de baixa biodegradabilidade, alta concentração de nitrogênio e íons metálicos. Esse trabalho buscou formas de aumentar a biodegradabilidade do chorume de um aterro sanitário utilizando método físico-químico e processos de separação com membranas. Após a caracterização do chorume, testes de coagulação/floculação, variando o tipo (cloreto férrico e sulfato de alumínio) e a concentração de agente químico (entre 100 e 2000 ppm), e experimentos com uma membrana de ultrafiltração $(50 \mathrm{kDa})$ foram realizados a fim de avaliar a relação DBO/DQO da amostra antes e após o experimento (ou seja, o aumento da biodegradabilidade da mesma). Foi verificado um aumento na biodegradabilidade de até $40 \%$ utilizando o método físico-químico e de até $67 \%$ utilizando a membrana de ultrafiltração.
\end{abstract}

\section{INTRODUÇÃO}

Segundo pesquisa realizada pelo Instituto Brasileiro de Geografia e Estatística (IBGE) Pesquisa Nacional de Saneamento Básico de 2008 - o Brasil produz cerca de 200 mil toneladas de resíduos sólidos urbanos (RSU) diariamente, onde cerca de 50\% destes são depositados em vazadouros a céu aberto. Os outros 50\% são depositados em aterros sanitários (aproximadamente 27\%) e aterros controlados (aproximadamente 23\%).

Uma das grandes desvantagens de dispor esses resíduos em aterros sanitários é a geração de um efluente líquido com elevada instabilidade termodinâmica - devido à presença de compostos não estabilizados derivados da decomposição parcial da matéria orgânica e com uma série de compostos naturais sintéticos dissolvidos e suspensos. Tal efluente, se não tratado corretamente, pode ocasionar séria depreciação à qualidade de vida das populações que o produzem (Fleck, 2003). A falta de tratamento ou o tratamento inadequado do chorume é um grave problema para o meio ambiente. A grande quantidade de chorume gerado nos aterros, a elevada carga orgânica e a variedade de outros contaminantes que esse efluente pode conter tornam seu tratamento difícil e oneroso. Pode-se afirmar que não existe um tratamento ideal para o chorume; de modo geral, se aplicam tratamentos semelhantes aos utilizados para águas residuárias, sendo os mais utilizados os tratamentos biológicos. 


\section{9 a 22 de outubro de 2014 \\ Florianópolis/SC}

O chorume gerado nos aterros sanitários contém alta quantidade de matéria orgânica, elevada concentração de nitrogênio e apresenta íons metálicos. A matéria orgânica presente no chorume contém quantidades significativas de substâncias húmicas e substâncias recalcitrantes; estas, por sua vez, são refratárias à biodegradação, a qual é a base para os processos mais utilizados no tratamento de chorume. Devido a estas características, os tratamentos convencionais têm sua eficiência limitada quando usados para tratar este lixiviado.

A biodegradabilidade é a capacidade de uma substância ser decomposta em substâncias mais simples pela ação de bactérias. Quanto maior a taxa de biodegradabilidade, mais facilmente o chorume pode ser tratado biologicamente (Kewu et al., 2008). A biodegradabilidade é medida através da razão entre a Demanda Biológica de Oxigênio e a Demanda Química de Oxigênio $\left(\mathrm{DBO}_{5} / \mathrm{DQO}\right)$. As substâncias mais complexas do lixiviado são mensuradas pelo parâmetro de DQO, que mede a quantidade de oxigênio necessário para degradar as substâncias químicas presentes no efluente; a DBO mede a quantidade de oxigênio necessário para degradar as substâncias biológicas e de fácil acesso às moléculas presentes no efluente. Por este motivo, essa razão tende a diminuir de acordo com o tempo de disposição do efluente - onde as substâncias biológicas são consumidas mais rapidamente que as substâncias químicas mais complexas.

A avaliação da biodegradabilidade aeróbia subsidia a determinação da concepção de sistemas de tratamento aeróbios mais adequados para uma condição específica, podendo evitar problemas futuros, como baixas eficiências e custos elevados de manutenção de operação.

A biodegradabilidade do efluente é afetada por muitos fatores, onde os mais relevantes são: fonte e quantidade de microrganismos e condições físico-químicas do meio (concentração de oxigênio, temperatura, $\mathrm{pH}$, dentre outros). Bila (2000) e Mota et al (1998) apontam a presença de material recalcitrantes em chorumes gerados em aterros sanitários estabilizados como responsável pela baixa biodegradabilidade dos mesmos.

Dentro deste contexto, o objetivo deste trabalho é avaliar o efeito de métodos físicoquímicos e da aplicação de processos de separação por membranas no aumento da biodegradabilidade de amostras de chorume provenientes de um aterro sanitário. Para tanto, dois agentes químicos (cloreto férrico e sulfato de alumínio) foram avaliados, em diferentes concentrações (entre 100 e 2000 ppm) e foi testada a ultrafiltração das amostras de chorume (bruto e pré-tratada pelo processo físico-químico) com uma membrana de massa molar de corte (MMC) de $50 \mathrm{kDA}$.

\section{MATERIAIS E MÉTODOS}

As amostras de chorume utilizadas no presente trabalho são provenientes de um aterro sanitário e foram caracterizadas quanto ao pH, DQO e DBO; as análises seguiram as normas contidas no Standard Methods (Eaton et al., 1995).

Primeiramente, avaliou-se a eficiência de um método físico-químico de coagulação e floculação no aumento da biodegradabilidade das amostras de chorume. Para tanto, foram 


\section{9 a 22 de outubro de 2014 \\ Florianópolis/SC}

realizados testes de jarros, em triplicata, testando-se dois coagulantes diferentes (sulfato de alumínio $\left(\mathrm{Al}_{2}\left(\mathrm{SO}_{4}\right)_{3}\right)$ e cloreto férrico $\left(\mathrm{FeCl}_{3}\right)$ ), em diversas concentrações (entre 100 e 2000 ppm). O procedimento dos testes de jarros realizados encontra-se descrito a seguir: (a) foram colocados $1.700 \mathrm{~mL}$ de amostra de chorume em jarros de $2 \mathrm{~L}$; (b) a amostra foi colocada sob agitação durante 5 minutos, na velocidade de 60 rpm para homogeneização; (c) a solução de coagulante, na concentração indicada, foi adicionada ao jarro com amostra, sob agitação rápida (150 rpm), por 5 min; (d) agitação lenta (30 rpm), por $30 \mathrm{~min}$; (e) decantação da amostra durante 30 minutos. Não houve ajuste de $\mathrm{pH}$ durante o experimento.

Para avaliação do efeito de processos de separação por membranas no aumento da biodegradabilidade da amostra, uma membrana de ultrafiltração, com MMC de $50 \mathrm{kDa}$ foi testada. Esta membrana, fornecida pela Andritz Separation, era cerâmica, tubular, com $250 \mathrm{~mm}$ de comprimento e 6 e $10 \mathrm{~mm}$ de diâmetro interno e externo, respectivamente; a área de permeação era, portanto, de 47,12 cm².

Um fluxograma esquemático do sistema de membranas utilizado pode ser observado na Figura 1. Este era constituído por um tanque de alimentação de acrílico (E-1), com 26 L de capacidade, com sistema de aquecimento por serpentina ligado a um banho (HAAKE DC-30) para controle da temperatura, uma bomba de deslocamento positivo (E-2, PROCON), para transporte do fluido (água ou chorume) através da tubulação, um pré-filtro (E-4, Hidro Filter, Hidro Filtros do Brasil Ind. E Com. Filtros Ltda., com tamanho nominal de poros de $1 \mu \mathrm{m}$ ), cujo objetivo é a retenção de partículas suspensas que possam incrustar na membrana, e um módulo de aço inoxidável para membranas tubulares (E-3).

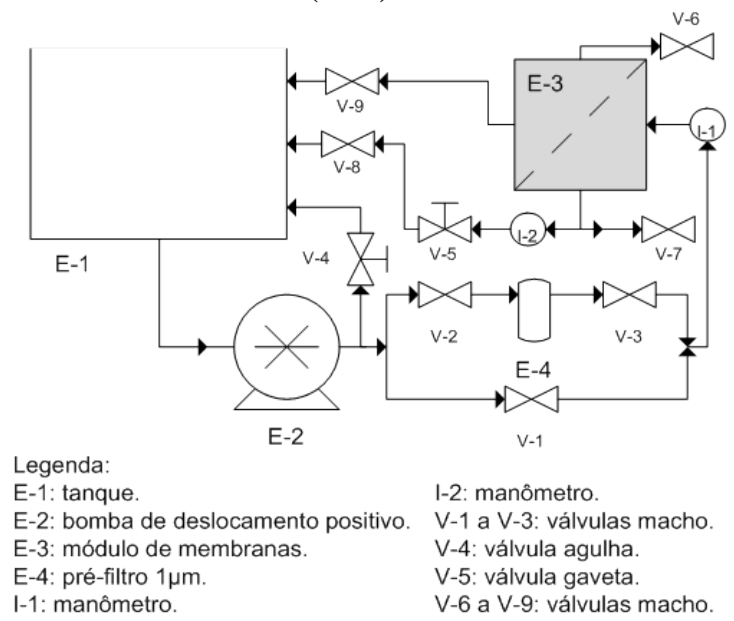

Figura 1: Fluxograma esquemático do sistema de membranas

Os experimentos de ultrafiltração envolveram, primeiramente, a caracterização da membrana em estudo, com a determinação do fluxo permeado de água destilada da membrana em diferentes pressões (entre 1 e 5 bar), na temperatura de $25^{\circ} \mathrm{C}$ e velocidade de alimentação de $4 \mathrm{~m} / \mathrm{s}$. Após estes testes, realizaram-se experimentos com o chorume como solução de alimentação: determinou-se, primeiramente, o fluxo permeado de chorume, de modo semelhante ao apresentado para a caracterização com água destilada, a fim de determinar o fluxo limite e a 
melhor pressão de operação; após a escolha desta (3 bar), operou-se o sistema durante 5h, a $25^{\circ} \mathrm{C}$, coletando-se o permeado gerado, a fim de avaliar a diminuição do fluxo permeado e o aumento da biodegradabilidade da amostra. A medida do fluxo permeado de água destilada antes e após a filtração do chorume permitiu a determinação da tendência ao fouling da membrana (Cassini, 2011). Após os experimentos de filtração do chorume, com o objetivo de restituir as características de fluxo e retenção da membrana, e também prevenir o desenvolvimento de microrganismos no sistema, adotou-se o procedimento de limpeza química indicado pelo fabricante das mesmas (Cassini, 2011).

\section{RESULTADOS E DISCUSSÃO}

Os testes de jarros foram realizados segundo procedimento descrito no item 2. A Figura 2 apresenta a razão DBO/DQO da amostra de chorume em função da concentração de agente químico utilizada.

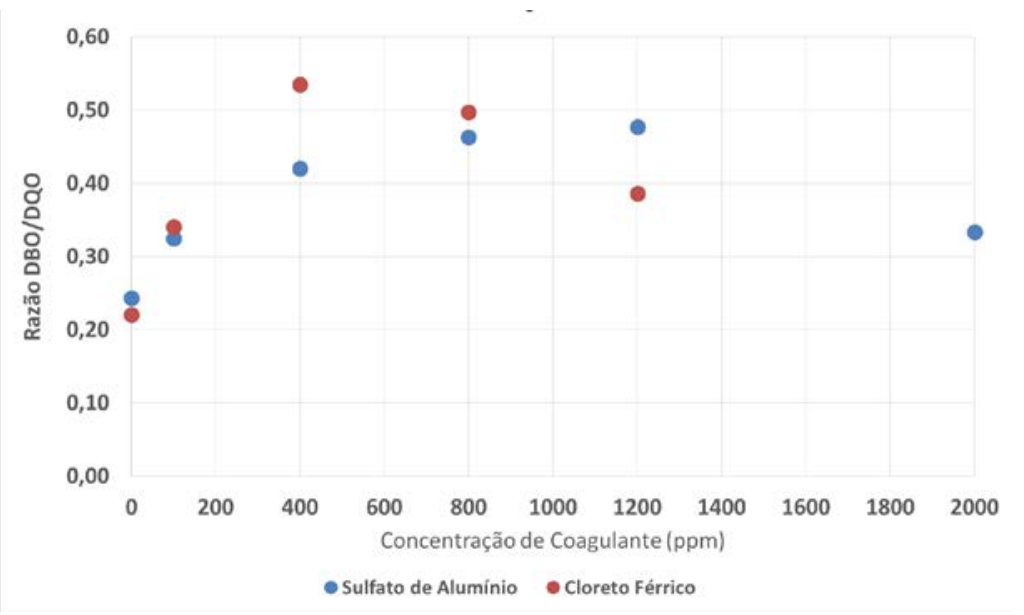

Figura 2: Efeito da concentração de cloreto férrico e de sulfato de alumínio na razão DBO/DQO das amostras de chorume.

O comportamento da curva de razão DBO/DQO em função do aumento da concentração de coagulante mostrado na Figura 2 concorda com os dados da literatura (Kewu et al, 2008). Esse comportamento se deve ao fato de que, à medida que aumentamos a concentração de coagulante este remove não somente os componentes recalcitrantes presentes no chorume, mas também o material menor e biodegradável. Dessa forma, existe um ponto ótimo de operação para remoção de DQO sem que essa afete significativamente a razão entre DBO/DQO.

Como pode ser observado na Figura 2, a concentração ótima encontrada (maior razão DBO/DQO) foi entre 800 e 1200 ppm para o sulfato de alumínio e de 400 ppm para o cloreto férrico. Este, portanto, mostrou-se mais eficiente na remoção das substâncias recalcitrantes: com uma concentração de 400 ppm de cloreto férrico elevou-se em 0,3 a razão DBO/DQO entre a amostra de chorume bruto e de chorume após o tratamento físico-químico; concentrações entre 800 e 1200 ppm de sulfato de alumínio não foram suficientes para se atingir o mesmo aumento. 
Durante ambos os testes, o pH da amostra não foi controlado, pois alguns autores observaram que o controle de $\mathrm{pH}$ de amostras de chorume não é necessário, desde que o mesmo se encontre entre 6 e 10 (Tatsi et al., 2003; Kewu et al., 2008). O pH da amostra de chorume utilizada nos experimentos de coagulação/floculação estava em 8,2 e variou até 7,4 em função da adição dos agentes químicos.

Ambos os coagulantes apresentaram boas eficiências na remoção total de DQO do chorume bruto. Para altas concentrações de agente químico, a remoção ultrapassou valores de até $50 \%$ durante a utilização de cloreto férrico como coagulante. Esse valor está acima dos apresentados na literatura. Silva et al. (2004) apresentaram valores de eficiência de remoção de até $25 \%$ para o cloreto férrico, enquanto Maleki et al. (2009), conseguiram remoções de até 28\%; Tatsi et al. (2003) afirma que, quanto maior a quantidade de cloreto férrico adicionado ao chorume, maior será a taxa de remoção de DQO. Segundo o autor, esse valor pode atingir até 75\%. Kewu et al. (2008) relatam uma remoção de DQO de 43,6\%, para o uso do cloreto férrico na concentração e pH ótimo de coagulação. Estes autores ressaltam que a remoção de DQO este relacionada à idade do aterro: para aterros mais recentes, com chorume menos estabilizado, a remoção de DQO obtida com processos físico-químicos é menor do que aquela observada para o chorume estabilizado ou parcialmente estabilizado.

A Figura 3 mostra o fluxo permeado de água destilada, de chorume bruto e de chorume pré-tratado com 400 ppm de cloreto férrico através da membrana de ultrafiltração, com MMC de $50 \mathrm{kDa}$, a $25^{\circ} \mathrm{C}$, versus a pressão transmembrana correspondente. Os experimentos foram realizados em modo de operação de reciclo total e com velocidade de alimentação igual a 4 m/s.

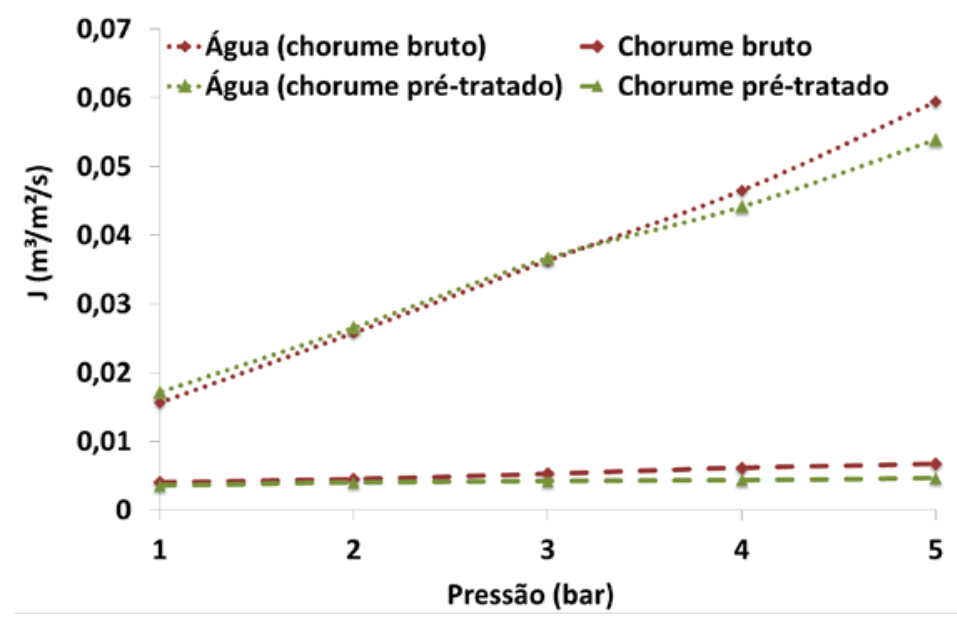

Figura 3: Fluxo permeado de água destilada e de chorume, pré-tratado e bruto, através da membrana de ultrafiltração, em função da variação da pressão transmembrana.

Como pode-se observar na Figura 3, o fluxo permeado de água destilada foi superior ao fluxo permeado de chorume submetido ao pré-tratamento, ou não. Este é um comportamento esperado, em função dos contaminantes presentes nas amostras de efluentes, que reduzem o fluxo através da membrana (Cassini, 2011). Ao contrário do que se esperava, entretanto, o fluxo 


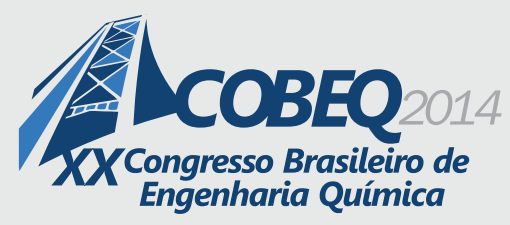

19 a 22 de outubro de 2014
Florianópolis/SC

permeado de chorume pré-tratado através da membrana estudada foi praticamente igual ao fluxo permeado de chorume bruto, indicando que a remoção de parte dos sólidos durante o prétratamento não acarretou em um aumento perceptível no fluxo permeado.

Observando ainda a Figura 3, pode-se notar que há pouca diferente do fluxo permeado de chorume em função da pressão transmembrana, mostrando que a utilização de uma pressão menor é mais interessante do ponto de vista econômico e não acarreta em extensa diminuição do fluxo permeado. Assim, optou-se pela utilização da pressão de 3 bar para os experimentos de avaliação do aumento de biodegradabilidade do chorume. Essa pressão foi escolhida, também, por estar abaixo do fluxo crítico para a membrana testada e por não apresentar problemas de operação do sistema (como vazamentos). Essa pressão também foi utilizada por Bohdziewicz et al (2008) em processos de ultrafiltração no tratamento de chorume. Kewu et al (2008) realizou experimentos variando a pressão transmembrana de operação e observou que quanto maior a pressão utilizada menor seria a eficiência de remoção de $\mathrm{DQO}$, pois quanto maior o $\Delta \mathrm{P}$, algumas macromoléculas não biodegradáveis e metais tóxicos podem passar pela superfície da membrana mais facilmente - esse comportamento também aumenta a incidência de fouling na membrana.

O experimento de avaliação de aumento da biodegradabilidade do chorume foi realizado na pressão 3 bar e operou-se o equipamento por, em média, 5 h. Durante o tempo de realização do experimento foi coletado todo o permeado, enquanto o concentrado retornou ao tanque de alimentação. Na Figura 4 está apresentado o comportamento do fluxo permeado pelo tempo de operação do equipamento.

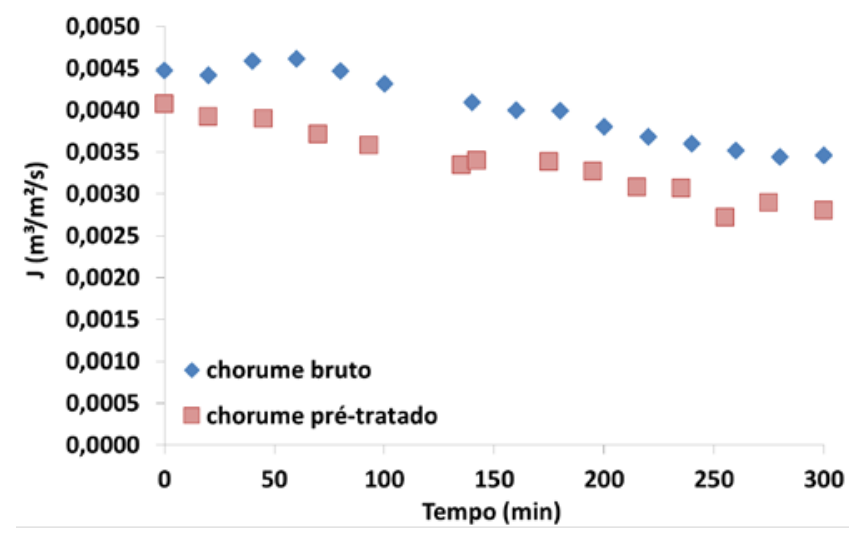

Figura 4: Comportamento do Fluxo de permeado de chorume bruto e pré-tratado, em função do tempo de filtração, na pressão de 3 bar.

Conforme era esperado, ocorreu uma redução do fluxo permeado ao longo do tempo de filtração; redução esta que pode ser explicada pela ocorrência dos fenômenos de polarização por concentração e fouling. O fluxo permeado da amostra que havia passado pelo pré-tratamento apresentou uma redução de $35 \%$ ao longo do experimento, enquanto que o fluxo permeado da amostra sem pré-tratamento apresentou uma redução de 39\%. Isso pode ser explicado pela remoção de sólidos que ocorre durante o pré-tratamento, diminuindo, assim, a ocorrência dos 
fenômenos causadores da redução do fluxo permeado.

As análise de DQO e DBO nas amostras de chorume bruto, de chorume pré-tratado e dos dois permeados obtidos demonstraram a eficiência da membrana de ultrafiltração na remoção dos componentes recalcitrantes do efluente estudado. A ultrafiltração do chorume bruto resultou em um aumento médio de 0,46 na razão DBO/DQO. O pré-tratamento com cloreto férrico resultou em um aumento de 0,2 na razão DBO/DQO, um pouco abaixo do obtido anteriormente, com as mesmas condições experimentais. A ultrafiltração do chorume pré-tratado resultou em um aumento médio de 0,35 na razão DBO/DQO; o aumento médio total da razão DBO/DQO para esta amostra (submetida, primeiramente, ao pré-tratamento com cloreto férrico e, após, à ultrafiltração), foi de, portanto, 0,55, atingindo-se uma razão DBO/DQO final de até 0,75.

A fim de avaliar a tendência ao fouling da membrana estudada, compararam-se os fluxos de água destilada antes e após a filtração das amostras de chorume (bruto e pré-tratado). Uma vez que o fenômeno de polarização por concentração ocorre somente durante a operação do sistema com a amostra de chorume, pode-se afirmar que a diminuição do fluxo percebida nestes testes deve-se, exclusivamente ao fouling (Cassini, 2011). A Figura 5 apresenta os fluxos permeados de água destilada obtidos antes (Fluxo inicial) e após (Fluxo Final) a passagem do chorume bruto e do chorume pré-tratado através da membrana de ultrafiltração, na temperatura de $25^{\circ} \mathrm{C}$ e velocidade de alimentação de $4 \mathrm{~m} / \mathrm{s}$.

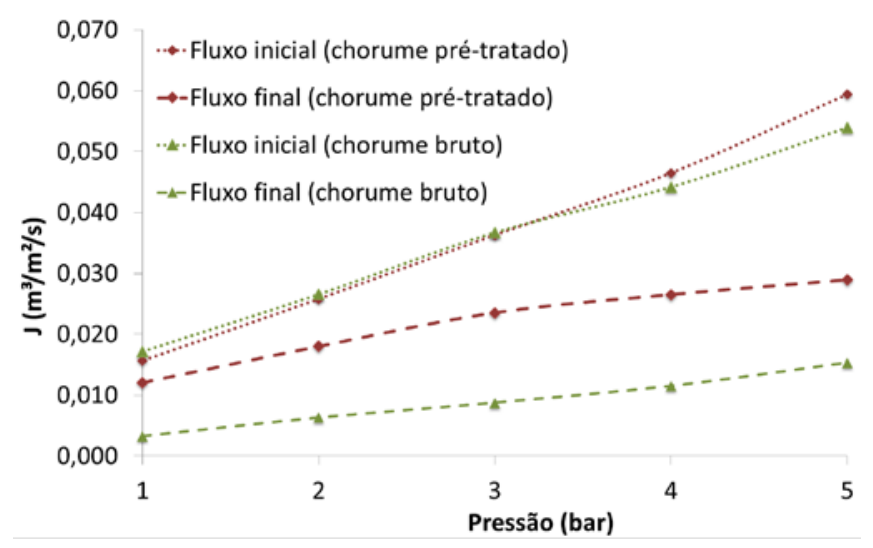

Figura 5: Diferença entre o fluxo de água destilada inicial e final (após a ultrafiltração do chorume bruto e pré-tratado.

A partir da Figura 5 pode-se perceber que a membrana utilizada possui uma tendência considerável à formação de fouling. A ultrafiltração do chorume bruto e do chorume pré-tratado resultaram em tendências ao fouling de $60 \%$ e $67 \%$, respectivamente. Era de se esperar que o chorume submetido previamente ao tratamento físico químico causasse uma menor tendência ao fouling na membrana, entretanto, ambos os processos apresentaram resultados muito semelhantes. Cassini et al. (2011) observou uma tendência ao fouling de $76 \%$ ao tratar um efluente proveniente da produção de isolados proteicos a base de soja com uma membrana semelhante, em condições semelhantes de experimento. 


\section{9 a 22 de outubro de 2014 \\ Florianópolis/SC}

\section{CONCLUSÕES}

O aumento da biodegradabilidade de amostras de chorume foi avaliado a partir da utilização de método físico-químico e da ultrafiltração com uma membrana tubular cerâmica. A concentração ótima de reagente encontrada (maior razão DBO/DQO) foi entre 800 e 1200 ppm para o sulfato de alumínio e de 400 ppm para o cloreto férrico. Este, portanto, mostrou-se mais eficiente na remoção das substâncias recalcitrantes das amostras de chorume nas condições avaliadas. A membrana utilizada demonstrou possuir uma tendência considerável à formação de fouling, nas condições estudadas: a ultrafiltração do chorume bruto e do chorume pré-tratado resultaram em tendências ao fouling de $60 \%$ e $67 \%$, respectivamente. A ultrafiltração do chorume bruto resultou em um aumento médio de 0,46 na razão DBO/DQO. O pré-tratamento com cloreto férrico resultou em um aumento de 0,2 na razão DBO/DQO. A ultrafiltração do chorume pré-tratado resultou em um aumento médio de 0,35 na razão DBO/DQO; o aumento médio total da razão DBO/DQO para esta amostra foi de, portanto, 0,55 , atingindo-se uma razão DBO/DQO final de até 0,75 .

\section{AGRADECIMENTOS}

Os autores agradecem à CAPES, ao CNPq e à FAPERGS pelo apoio financeiro.

\section{REFERÊNCIAS}

BILA, D.M. Aplicação de processos combinados no tratamento do chorume, Dissertação de Mestrado, UFRJ, Rio de Janeiro, Brasil, 2000.

BOHDZIEWICZ, J.; MICHAL, B., GÓRSKA, J. Application of pressure-driven membrane techniques to biological treatment of landfill leachate. Proc. Bioch. v.36, p. 641-646, 2001.

CASSINI, A. S., TESSARO, I. C., MARCZAK, L. D. F. Ultrafiltration of Wastewater from Isolated Soy Protein Production: Fouling Tendencies and Mechanisms, Sep. Sci. Tech., 46: 7, 1077 - 1086, 2011.

EATON, A.D., CLESCERI, L.S. e GREENBERG, A.E., Standards Methods for the examination of water and wastewater. $19^{\text {th }}$ edition. Washington: American Public Health Association, 1995.

FLECK, E. Sistema integrada por filtro anaeróbio, filtro biológico de baixa taxa e banhado construído aplicado ao tratamento de lixiviado de aterro sanitário. Dissertação de mestrado, UFRGS. Porto Alegre, RS, Brasil, 2003.

IBGE - INSTITUTO BRASILEIRO DE GEOGRAFIA E ESTATÍSTICA, 2002. Pesquisa

Nacional de Saneamento Básico, 2000. IBGE, 2002.

KEWU, P.; WENQI, G. Biodegradability enhancement of municipal landfill leachate. Wat. Sci. Eng. v.30 No.4, p. 89-98, 2008.

MOTA, S. Introdução à Engenharia Ambiental. ABES, Rio de Janeiro, 1998

SILVA, A.C., DEZOTTI, M., SANT’ANNA Jr, G.L., Treatment and detoxification of a sanitary landfill leachate. Chem,., 55: 207-214, 2004.

TATSI, A.A., ZOUBOULIS, A.I., MATIS, K.A., SAMARAS, P. Coagulation flocculation pretreatment of sanitary landfill leachates. Chem., 53: 737-744, 2003. 